EESTI NSV TEADUSTE AKADEEMIA TOIMETISED. 28. KCIDE

GEOLOOGIA. 1979, NR. 4

ИЗВЕСТИЯ АКАДЕМИИ НАУК ЭСТОНСКОЙ ССР. ТОМ 28

ГЕОЛОГИЯ. 1979, № 4

\title{
ПРОСЛЕЖИВАНИЕ КЕИЛАСКОГО ГОРИЗОНТА СРЕДНЕГО ОРДОВИКА В РАЗРЕЗАХ ВОСТОЧНОЙ ЛИТВЫ ПО ОСТРАКОДАМ
}

Кейлаский горизонт в Восточной Литве до сих пор установлен по брахиоподам Dalmanella kegelensis Alich., Leptaena rugosoides Orasp., Sowerbyella oеpiki Rõõm. и трилобиту Leiolichas illaenoides Schm. в разрезах скв. Лапес $(713,3-706,9$ м), Крякянава $(938,8-930,0$ м), Укмерге $(574,0-566,2$ м), Саснава $(887,0-881,5$ м) и Калвария $(912,2$ - 905,7 м) (Мянниль, 1966; Пашкевичюс, 1973). Материал по остракодам, собранный А. И. Нецкой, Л. Гайлите, Л. Сарвом и автором из кернов скв. Вильнюс, Жежмаряй, Крякянава, Лапес, Лядай, Саснава, Калвария, Паявонис-13, Укмерге, Лудза и др., также почти не содержит информации о фауне кейлаского времени. Единичные находки остракод Polyceratella spinosa Sarv, Neotsitrella longata (Sarv), Tallinnopsis ovalis Sarv, относящихся к этому времени, происходят лишь из разреза скв. Укмерге (неопубликованные данные Л. Сарва). На основании этого материала предполагалось, что остракодовая фауна идавереского-кейлаского горизонтов Восточной Литвы представлена одним комплексом (Сидаравичене, 1973). Обновление остракод на нижней границе кейлаского горизонта считалось нами практически не прослеживаемым из-за редкой встречаемости стратиграфически важных видов. В настоящей статье анализируется прослеживаемость фауны кейлаского горизонта Эстонии на территории всего Прибалтийского региона.

Изучено 126 проб весом 500-700 г, отобранных из разрезов скв. Друкшяй, Ляляй, Паукшчяй и Вирбалишкис идавереских-кейласких отложений (рис. $1-4)$. Кроме того, используются результаты по скв. Буткунай (материал находится в печати). Все скважины расположены в пределах Средне-Литовского прогиба, во внешней подзоне ВосточноПрибалтийской структурно-фациальной зоны (Решения..., 1978).

Граница кукрузеского и идавереского горизонтов в этих разрезах более или менее точно устанавливается по исчезновению Pseudostrepula kuckersiana (Bonnema), Polyceratella kuckersiana (Bonnema), Laccochilina? kuckersiana (Bonnema), Uhakiella pseudopumila Sid., Piretella sp. n., Chilobolbina sp. и появлению Tetrada memorabilis (Neckaja), Polyceratella aluverensis Sarv, Pedomphalella egregia (Sarv), Kiesowia frigida Sarv, Pyxion nitidum Sarv, Pentagona joehviensis (Sarv), Bichilina prima Sarv, Sigmobolbina porchowiensis (Neckaja), Pseudostrepula asymmetrica Neckaja. Появившийся в идавереском горизонте комплекс остракод, постепенно обогащаясь, прослеживается до кейлаского горизонта. Идавереский и йыхвиский гори- 


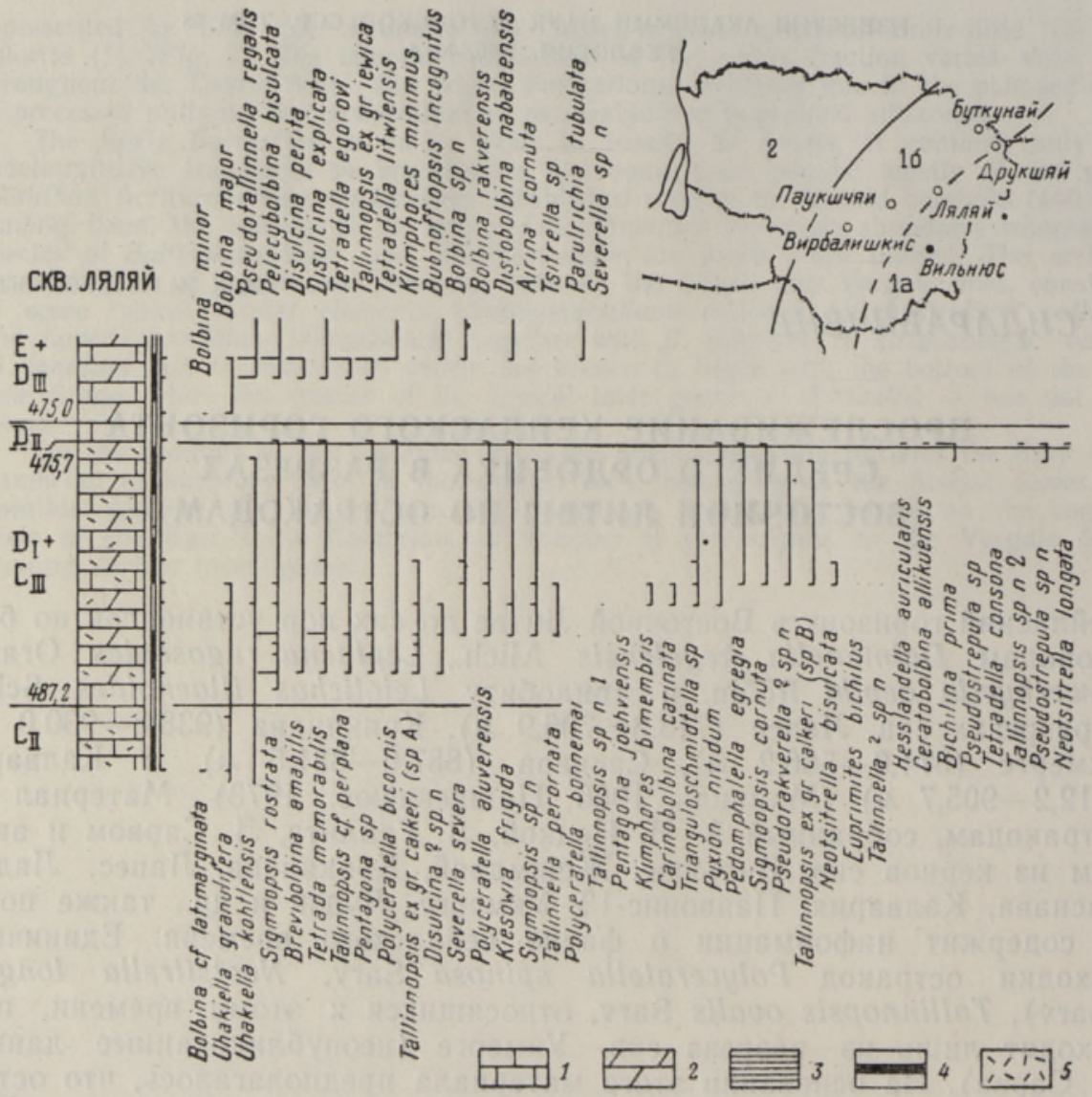

Рис. 1. Распределение остракод в отложениях идавереского-кейлаского горизонтов разреза скв. Ляляй. 1 - известняк, 2 - мергель, 3 - аргиллит, $4-$ метабентонит, 5 - органогенно-обломочный материал. $\mathrm{C}_{\mathrm{II}}$ - кукрузеский, $\mathrm{C}_{\mathrm{III}}$ - идавереский, $\mathrm{D}_{\mathrm{I}}$ - йыхвиский, $\mathrm{D}_{\mathrm{II}}$ - кейлаский, $\mathrm{D}_{\mathrm{III}}$ - оандуский, $\mathrm{E}$ раквереский, $\mathrm{F}_{\mathrm{Ia}}$ - набалаский горизонты. На схеме: 1 - Восточно-Прибалтнйская структурно-фациальная зона, $1 a-$ внутренняя подзона, 16 - внеш-

няя подзона, 2 - Западно-Прибалтийская структурно-фациальная зона.

зонты в скв. Друкшяй, Ляляй и Паукшчяй представлены известняками сероцветными, волнисто-слоистыми или мелкокомковатыми, органогенно-обломочными, с прослойками мергелей, количество которых вверх по разрезам и к юго-западу увеличивается. В верхней части разреза Вирбалишкис залегают массивные голубовато-серые мергели без органогенно-обломочного материала. В разрезах скв. Паукшчяй (гл. $542,5-542,8$ м) и Вирбалишкис (гл. 857,4 м) обнаружены одна или несколько тонких (до 2 см) прослоек метабентонитов, которые сравнимы с метабентонитами верхней границы известняков Dalby в Швеции и относятся к верхам идавереского горизонта (Чехавичюс, Сидаравичене, 1978).

Фауна кейлаского горизонта обнаружена в кернах скв. Буткунай, Друкшяй, Ляляй и Вирбалишкис. Она представлена следуюшими видами: Pyxion keilaensis Sarv, Neotsitrella longata (Sarv), Tallinnopsis ordinata Sarv, T. ovalis Sarv, T. excisa (Sid.), T. grandis Sarv, Polyceratella spinosa Sarv, Pseudostrepula estona Sarv, Euprimites kahalaen- 


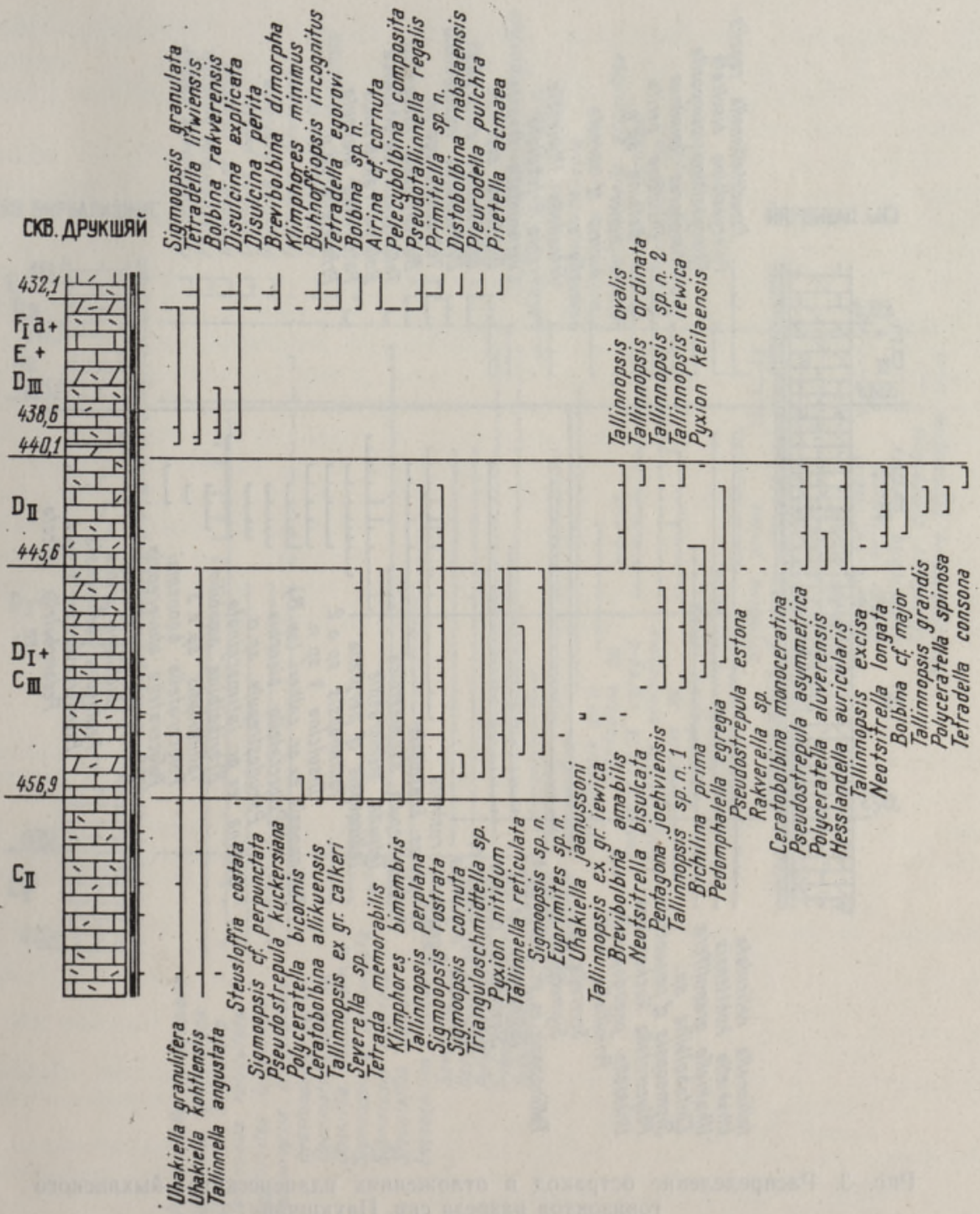

Рис. 2. Распределение остракод в отложениях идавереского-кейлаского горизонтов разреза скв. Друкшяй.

sis Sarv. Все эти виды, за исключением двух последних, которые переходят в вышезалегающие слои, до сих пор известны только из кейлаского горизонта (Сарв, 1959; Рымусокс, 1970 и др.). Появлению этих видов предшествует исчезновение Uhakiella jaanussoni (Schallreuter), U. kohtlensis (Opik), Severella severa (Sarv), Sigmoopsis cornuta (Krause), Hesslandella panis Schallr., Tetrada memorabilis (Neckaja), Ceratobolbina allikuensis (Sarv).

В разрезе Буткунай фауна кейлаского горизонта относится к почти двадцатиметровой $(674,5-655,1$ м $)$ вилучяйской пачке межциемской свиты (голубовато-серые тонко-слоистые мергели, почти не содержащие органогенно-обломочного материала). Мергели, схожие с вилучяйскими, отмечены и в разрезе скв. Вирбалишкис, расположенной, как 


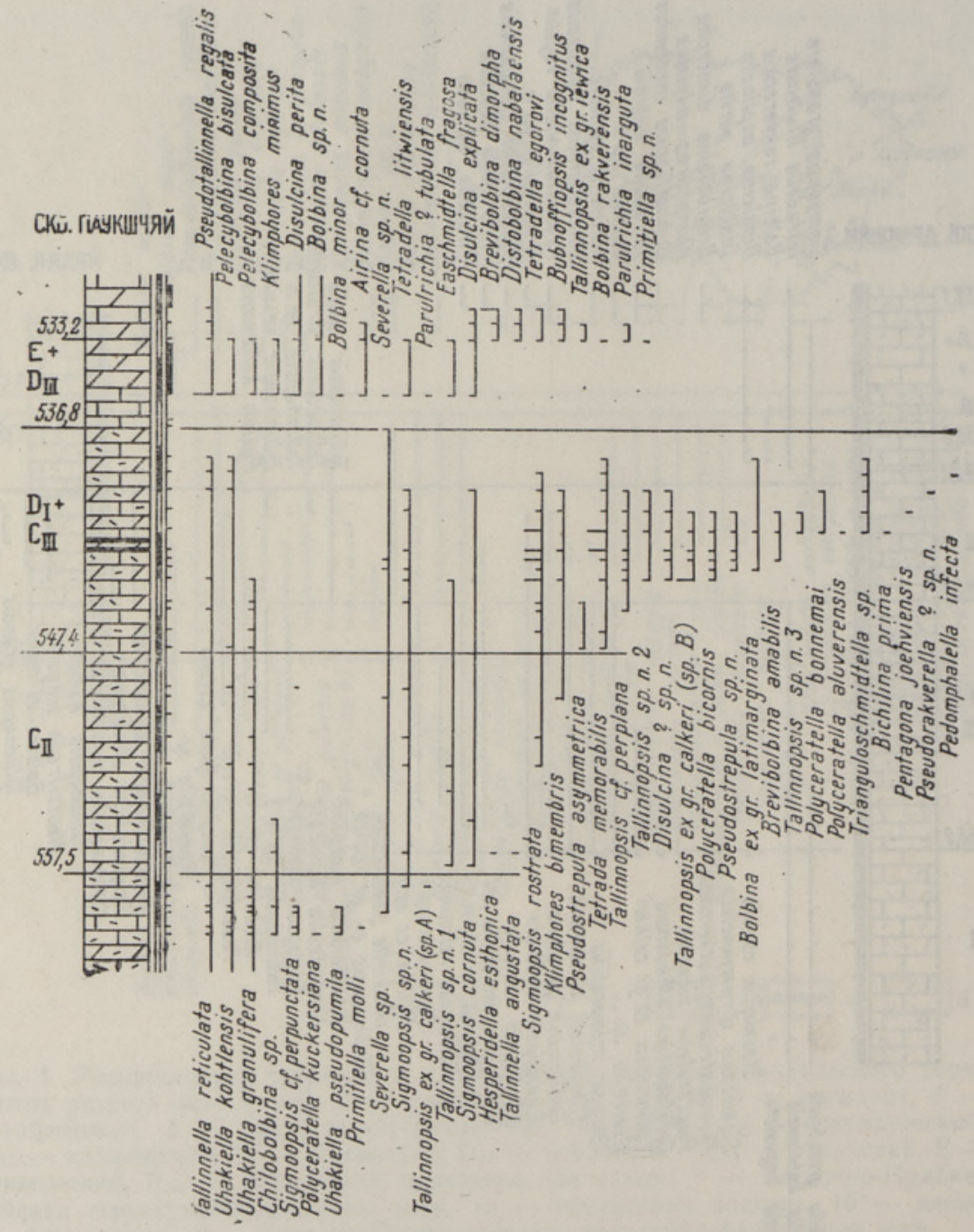

Рис. 3. Распределение остракод в отложениях идавереского-йыхвиского горизонтов разреза скв. Паукшчяй.

и скв. Буткунай, в осевой части Средне-Литовского прогиба. Они залегают здесь на глубине $852,0-843,8$ м. В отличие от мергелей разреза Буткунай эти мергели содержат здесь остракоды идавереского и йыхвиского горизонтов, и лишь в верхней части, начиная примерно с глубины 845,2 м, появляются виды кейлаского времени Pyxion keilaensis Sarv, Neotsitrella longata (Sarv) и др. Фауна кейлаского горизонта в разрезе Вирбалишкис обнаружена и в вышезалегающих детритовых мергелях и известняках (интервал $843,8-841,5$ м).

В разрезах Друкшяй и Ляляй, расположенных восточнее оси Средне-Литовского прогиба (линии Буткунай-Вирбалишкис), вилучяйская пачка отсутствует. Остракоды, характерные для кейлаского горизонта, здесь найдены в серых детриғовых известняках. Верхняя граница горизонта в разрезе Друкшяй палеонтологически четкая и приурочена к появлению в известняках прослоев темно-серого аргил- 


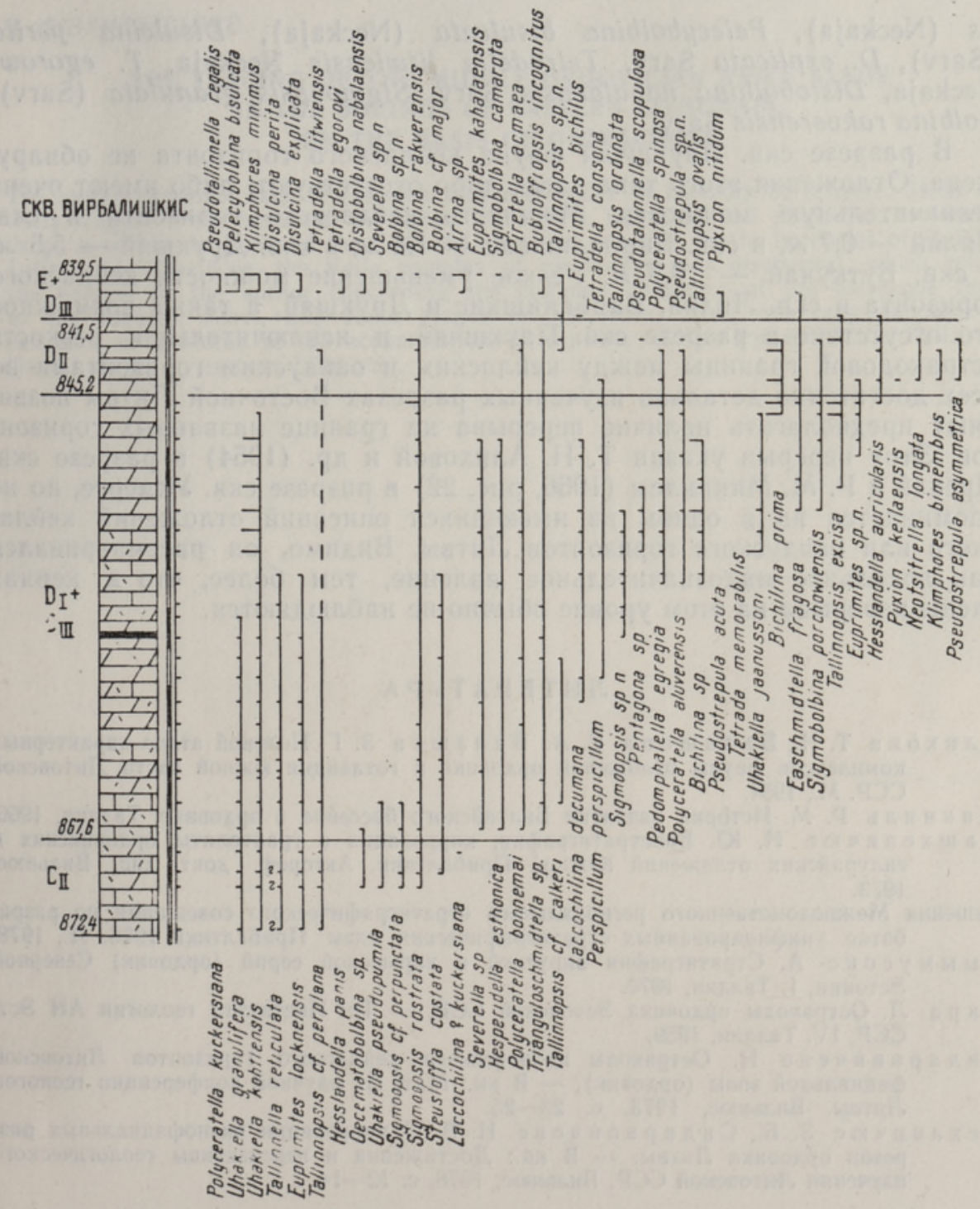

Рис. 4. Распределение остракод в отложениях идавереского-кейлаского горизонтов разреза скв. Вирбалишкис.

лита. Аналогичное изменение пород на этом уровне наблюдается и в разрезе скв. Ляляй. Здесь над кейласкими известняками залегают мергели, переслаивающиеся с известняками $(475,0-471,0$ м), в нижней части которых остракоды практически не обнаружены. По аналогии с разрезом скв. Друкшяй этот разрез отнесен нами к оандускому горизонту.

Верхняя граница кейлаского горизонта в изученных разрезах является уровнем самого существенного изменения остракод за весь ордовикский период. Фауна этого горизонта резко и почти полностью сменяется богатым комплексом оандуского и раквереского горизонтов, представленным Klimphores minimus (Sarv), Pseudotallinnella rega- 
lis (Neckaja), Pelecybolbina bisulcata (Neckaja), Disulcina perita (Sarv), D. explicata Sarv, Tetradella litwiensis Neckaja, T. egorowi Neckaja, Distobolbina nabalaensis Sarv, Sigmoopsis granulata (Sarv), Bolbina rakverensis Sarv.

В разрезе скв. Паукшчяй фауна кейлаского горизонта не обнаружена. Отложения этого типа здесь либо отсутствуют, либо имеют очень незначительную мощность. Мощность кейлаского горизонта в скв. Ляляй $-0,7 \mu$, в скв. Вирбалишкис $-1,4 \mu$, в скв. Друкшяй $-5,5 \mu$, в скв. Буткунай - 19,5 м. Резкое уменьшение мощности кейлаского горизонта в скв. Ляляй, Вирбалишкис и Друкшяй, а также возможное его отсутствие в разрезе скв. Паукшчяй и исключительная резкость остракодовой границы между кейласким и оандуским горизонтами во всех достаточно детально изученных разрезах Восточной Литвы позволяют предполагать наличие перерыва на границе названных горизонтов. Этот перерыв указан Т. Н. Алиховой и др. (1954) в разрезе скв. Пренай и Р. М. Мяннилем (1966, рис. 22) в разрезе скв. Укмерге, но не упоминается ни в одном из имеющихся описаний отложений кейлаского или оандуского горизонтов Литвы. Видимо, он рассматривался как локальное малозначительное явление, тем более, что в кернах следы перерыва на этом уровне обычно не наблюдаются.

\section{ЛИТЕРА Т Р Р А}

Ал и хов а Т. Н., Бал ашов а Е. А., Б ал а шо в З. Г. Полевой атлас характерных комплексов фауны отложений ордовика и готландия южной части Литовской CCP. M., 1954.

М яннил в Р. М. История развития Балтийского бассейна в ордовике. Таллин, 1966.

Пашке в и ю с И. Ю. Биостратиграфия, корреляция и граптолиты ордовикских и силурийских отложений Южной Прибалтики. Автореф. докт. дис. Вильнюс, 1973.

Решения Межведомственного регионального стратиграфического совещания по разработке унифицированных стратиграфнческих схем Прибалтики 1976. Л., 1978.

Ры ымусокс А. Стратиграфия вируской и харьюской серий (ордовик) Северной Эстонии, I. Таллин, 1970.

С а р в Л. Остракоды ордовика Эстонской ССР. - Тр. Института геологии АН Эст. CCP, IV. Таллин, 1959.

С ид а ра вичен е Н. Остракоды идавереского-кейлаского горизонтов Литовской фациальной зоны (ордовик). - В кн.: Мат. III научной конференции геологов Литвы. Вильнюс, 1973, с. 23-25.

Чех а в и юс 3. Б., С ид а р а в и ене Н. В. О корреляции разнофациальных разрезов ордовика Литвы. - В кн.: Достижения и перспективы геологического изучения Литовской ССР. Вильнюс, 1978 , с. $12-14$.

Литовский научно-исследовательский геологоразведочный институт

Поступила в редакцию $17 / \mathrm{V} 1979$

\section{N. SIDARAVICIENE}

\section{KESKORDOVIITSIUMI KEILA LADEME IDA-LEEDU LÄBILOIGETE ANALOUS OSTRAKOODIDE PŌHJAL}

On esitatud idavere, jōhvi ja keila lademe ostrakoodide uurimise tulemused Ida-Leedu Leliai, Virbališkise, Drūkšiai ja Paukščiai puursüdamike andmeil. Drūkšiai, Leliai ja Virbališkise puursüdamikest on leitud keila lademele iseloomulik ostrakoodide kompleks, mille olemasolu lükkab ümber autori senise seisukoha, nagu oleks idavere, jōhvi ja keila lademe ostrakoodidefauna Leedus samailmeline. On oletatud settelünga olemasolu keila ja oandu lademe piiril Ida-Leedus. 


\section{N. SIDARAVICIENE}

\section{THE TRACING OF THE MIDDLE ORDOVICIAN KEILA STAGE IN THE BORINGS OF EASTERN LITHUANIA, ON THE BASIS OF OSTRACODES}

The author presents data of research into ostracodes in deposits of Idavere, Jõhvi and Keila stages, in the boreholes of Leliai, Virbališkis, Drūkšiai, and Paukščiai, eastern Lithuania, within the limits of the Central-Lithuanian syncline. In the boreholes of Drūkšiai, Leliai and Virbališkis, the Keila complex of ostracodes was discovered, which refutes the opinion of the author concerning the common character of the ostracode fauna of the Idavere, Jõhvi, and Keila stages in Lithuania. Thus, one may suppose the existence of a hiatus in the accumulation of deposits at the border of the Keila and Oandu stages in eastern Lithuania. 